\title{
Formas de resistencia en la construcción de proyectos hidroeléctricos"
}

\author{
Gustavo Adolfo Muñoz Gaviria**
}

Recibido: 15 de julio de 2016

Evaluado: 10 de septiembre de 2016

Aceptado: 3 de octubre de 2016

\section{RESUMEN}

El presente trabajo explora las posibilidades de resistencia y de surgimiento de la crítica de las poblaciones impactadas por proyectos hidroeléctricos, y por las formas de violencia contenidas en las prácticas de lo que viene siendo denominado como "gestión social" en esos contextos. Se aborda esta forma de gestión como un dispositivo de gobierno, en el sentido de Foucault (1980), Deleuze (1991) y Dean (2010), compuesto por líneas de visibilidad, enunciación, poder y subjetividad, para conducir la interacción entre empresa, Estado y comunidades impactadas. Se entienden las formas de resistencia y de crítica como elementos de las líneas de subjetividad del dispositivo. Se realiza el estudio de caso de la central hidroeléctrica Porce III, construida en la década de 2000, en Colombia, para el cual se realiza un análisis de las percepciones y manifestaciones de la población afectada, con énfasis en las manifestaciones críticas al proceso de desplazamiento y reasentamiento, así como en sus respectivas fuentes de justificación. Los datos provienen de análisis documentales, del trabajo etnográfico y de la experiencia profesional previa del investigador en el reasentamiento estudiado. Se evidencia una variedad de estrategias discursivas y no discursivas, tendientes a subvertir el orden promovido por la racionalidad de gestión del dispositivo.

Palabras clave: centrales hidroeléctricas, reasentamiento, gestión social, violencia, Colombia. 


\section{Forms of Resistance in the Construction of Hydropower Projects}

\section{Abstract}

This work explores the possibilities of resistance and critique emergence of the populations impacted by hydropower projects and forms of violence contained in the practices of what is being called "Social Management" in such contexts. This form of management is approached as a government apparatus as in Foucault (1980), Deleuze (1991) and Dean (2010), composed by lines of visibility, enunciation, power and subjectivity for conducting the interaction among companies, the State and the impacted communities. The forms of critique and resistance are understood as elements of the apparatus's subjectivity lines. And analyses of perceptions and manifestations of the affected populations emphasizing in their critical declarations to the process of displacement and resettlement is made, as well as to their sources of justification. Data are provided by documental analyses, ethnographic work and the previous experience of the researcher in the studied resettlement. A variety of discursive and non-discursive strategies to subvert the order promoted by the managerial rationality of the apparatus is evidenced.

Keywords: hydropower plants, resettlement, social management, violence, Colombia.
Received: July 15, 2016

Evaluated: September 10, 2016

Accepted: October 3, 2016 


\section{Formas de resistência na construção de projetos hidroelétricos}

Recebido: 15 de julho de 2016

Avaliada: 10 de setembro de 2016

Aceito: 3 de outubro de 2016

\section{Resumo}

O presente trabalho explora as possibilidades de resistência e de surgimento da crítica das populações impactadas por projetos hidrelétricos e pelas formas de violência contidas nas práticas do que vem sendo chamado de "gestão social" em tais contextos. Aborda-se esta forma de gestão como um dispositivo de governo no sentido de Foucault (1980), Deleuze (1991) e Dean (2010), composto por linhas de visibilidade, enunciação, poder e subjetividade, para conduzir a interação entre empresa, Estado e comunidades atingidas. Entendem-se as formas de resistência e crítica como elementos das linhas de subjetividade do dispositivo. Estuda-se o caso da usina hidrelétrica Porce III, construída na década de 2000, na Colômbia, para o qual se faz uma analise das percepções e manifestações da população afetada, fazendo ênfase nas manifestações críticas ao processo de deslocamento e reassentamento; bem como nas suas respectivas fontes de justificação. Os dados provêm de análise documental, do trabalho de campo e da experiência profissional do pesquisador no reassentamento estudado. Evidencia-se uma variedade de estratégias discursivas e não discursivas tendentes a subverter a ordem promovida pela racionalidade de gestão do dispositivo.

Palavras-chave: usinas hidrelétricas, reassentamento, gestão social, violência, Colômbia. 


\section{INTRODUCCIÓN}

La historia de América Latina, desde la época de la Colonia, está marcada por el uso de la violencia (González, 2014; Palacios, 2003) para el sometimiento y la dominación de los pueblos tradicionales. El caso colombiano es una muestra clara del uso de diversas formas de violencia para el despojo de tierras y su posterior concentración. Estas formas de violencia han conocido su origen en coaliciones de fuerzas provenientes de todo el espectro ideológico, y otras incluso sin ideología, impulsadas por el narcotráfico. El ejercicio de la violencia armada ha provenido también del Estado.

Si bien en los últimos años se han logrado avances hacia la desmovilización de los principales grupos armados, lo que viene reduciendo significativamente los índices de violencia en el país, existen otras fuentes de violencia susceptibles de generar una revictimización de la población. Una de esas fuentes de violencia es el propio modelo de "desarrollo", intensivo en capital, que actúa por acumulación por desposesión (Harvey, 2005) de las poblaciones de menores recursos, más claramente en zonas rurales.

Las nuevas formas de violencia que, sin embargo, no excluyen la violencia armada, están en gran medida contenidas en los arreglos institucionales que regulan la interacción entre empresas y comunidades, en el contexto de lo que se denomina "grandes proyectos de desarrollo", más específicamente en las políticas de licenciamiento ambiental. Se trata de diversas formas de violencia ejercidas en las prácticas estatales, de las empresas y sus consultores. Entre ellas identificábamos, en un trabajo anterior
(Muñoz, 2015), violencias simbólicas, epistemológicas, de género, etc., agrupadas en institucionalizadas y no institucionalizadas, como se ampliará más adelante.

Frente a este contexto de ejercicio de nuevas formas de violencia y de riesgo de revictimización de las comunidades rurales, cabe preguntarse por las evidencias de resistencia que los impactados por ese tipo de proyectos han usado para salvaguardar sus derechos e intereses. Algunos trabajos han abordado esta cuestión, como el de Vainer y Araújo (1990), que reconstruye la historia del Movimiento de los Impactados por Represa (MAB), en Brasil, y sus estrategias de lucha; el de Vieira (2003), que discute el proceso de articulación de ese movimiento a la Comisión Mundial de Represas (WCD); el de Da Rocha (2014), que analiza lo que denomina la "condición de impactado por represas", al resaltar el carácter procesual de la implantación de las represas y una consecuente configuración estratégica de identidades diversas, por medio de las etapas de dichos proyectos; y finalmente, el de Guedes (2006), que analiza los cursos de formación de los militantes del MAB como prácticas de formación de identidad.

El presente trabajo profundiza en el análisis de las prácticas y efectos de lo que viene siendo denominado "gestión social" en grandes proyectos, entendida como un dispositivo de gobierno, en el sentido de Foucault (1980); un dispositivo que pretendería dar forma a las vidas de los impactados después del reasentamiento. Se analizaron, en un trabajo anterior y siguiendo la pista de Foucault (1980), Deleuze (1991) y Dean (2010), cuatro dimensiones del dispositivo: de visibilidad o de creación de objetos de 
gobierno, técnica o de poder, o de saber y de subjetividad (Muñoz, 2016). Se entendía allí la dimensión subjetiva como compuesta por al menos dos elementos: la formación o promoción de identidades, y las formas de contraconducta o resistencia a dicho dispositivo de gobierno. Abordamos aquí el segundo componente de la dimensión o línea de subjetividad, buscando responder a la pregunta por las condiciones de posibilidad de resistir a las nuevas formas y racionalidades de gobierno, incluidas sus violencias, promovidas por las lógicas de la expansión del capital y de apropiación territorial de las grandes empresas; y así, rastrear la creatividad de las comunidades en tal empeño.

La central hidroeléctrica Porce III fue construida en la década de 2000 por la empresa pública de generación de energía Empresas Pública de Medellín (EPM); y comenzó operación en 2010, con una capacidad de generación de 660 MW. Impactó aproximadamente a 582 familias y 372 mineros (EPM, 2011), para un total de aproximadamente 2.700 personas. Solamente el $18 \%$ de los impactados fue compensado con la "restitución" de sus condiciones de vida y un acompañamiento por parte de la "gestión social", el resto de población fue indemnizado con dinero.

Desde lo teórico, nos ubicamos en los estudios del poder y las formas de gobierno en su relación con el saber, iniciados por Foucault; y desarrollados más tarde por otros autores. En sus cátedras sobre seguridad, territorio y población, Foucault (2008) entiende la actividad de gobierno como la conducción de la conducta de los otros, en lo que Deleuze (1991) denomina una madeja de líneas de visibilidad, enunciación, poder y subjetividad; las cuales configuran, en definitiva, un dispositivo de gobierno (Foucault, 1980 Deleuze, 1991, Dean 2010).

Existe para Foucault (2008), según lo permitan los dispositivos, la posibilidad de contraconductas o prácticas contrarias a la lógica o racionalidad de gobierno que los individuos o grupos adoptarían como formas de resistir a las prácticas de este. Esas formas de resistencia serán denominadas como formas de profanación del dispositivo por Agamben (2011), y aparecerán en Dean (2010) relacionadas con el concepto de problematización de los regímenes de gobierno.

Se hace también un puente teórico entre los conceptos de contraconducta o problematización, y el concepto de crítica en Boltanski (2014). Para este, existe una relación entre instituciones y crítica, que queremos poner en paralelo con los conceptos de dispositivo de gobierno y contraconducta de Foucault. Lo anterior, básicamente por considerar útil la aproximación de Boltanski al entendimiento de las fuentes de la crítica como una cuestión de justificación, en lo que algunos han denominado una sociología de la justificación o sociología pragmática de la crítica.

Como fuente de información empírica se usan las entrevistas realizadas en trabajo de campo durante 2013 y 2014, cuatro años después de efectuado el reasentamiento e iniciada la operación de la central.

En la siguiente sección agrupamos las problematizaciones de la población al proceso de desplazamiento y reasentamiento. Posteriormente, presentamos algunas manifestaciones que podrían indicar la existencia de resistencias o contraconductas de la 
población al dispositivo establecido por la "gestión social". Y, finalmente, analizamos la relación entre problematizaciones y resistencia.

\section{De PROBlematizaciones $Y$ SUJETOS CRÍTICOS}

Una problematización es para Dean (2010) la forma en que un actor pone en cuestión una actividad de gobierno o una manifestación de que el gobierno se ha tornado un problema para alguien. Encontramos correspondencia entre este concepto de problematización y lo que aparece en Boltanski y Thévenot (1999) como "inconformidad"1, que, según estos autores, terminaría en una "puesta en escena", en que "las personas están sometidas a un imperativo de justificación" (p. 367). La incertidumbre de esta puesta en escena permitiría en todo momento la posibilidad de cuestionar el orden establecido por las prácticas de gobierno. La manifestación de esa inconformidad es considerada por los autores como el momento de la crítica.

Queremos identificar en este trabajo qué prácticas de la población impactada constituirían ejemplos de contraconductas, de resistencias al dispositivo de la "gestión social", así como la relación que podría establecerse entre las manifestaciones críticas o problematizaciones puestas al dispositivo, y una actitud de resistencia frente a este.

Al buscar el diálogo entre los conceptos de contraconducta, crítica y problematización, pretendemos aprovechar el potencial de

1 La palabra en inglés es discontent, según el artículo de Boltanski consultado en este trabajo. la sociología pragmática de la crítica para aproximarnos a la crítica como ella es; es decir, para fundamentar la crítica en la realidad social (Del Moral García, 2009), al tiempo que se crea una base para un análisis de gubernamentalidad (Foucault, 2008, Dean, 2010) del dispositivo de gobierno en que los actores estarían insertos. Es decir, se estaría contribuyendo para tender un puente entre la crítica de los actores y la crítica teórica.

Se pretende averiguar, también, en qué grado los análisis de la sociología pragmática de la crítica permitirían evidenciar la existencia de: "[...] grados variables de sujeción y comprender de qué formas pueden los actores abrir vías que se orienten hacia la liberación, aunque fuera únicamente estableciendo zonas temporales de autonomía, de carácter necesariamente local, y, aún más, coordinando sus acciones con el propósito de cuestionar la necesidad de un orden social" (Boltanski, 2014, p. 81).

A continuación, agrupamos las problematizaciones de la población en tres momentos diferentes de la implementación de la central hidroeléctrica: antes de la construcción, durante el proceso de reasentamiento y pocos años después de la evaluación de los resultados por parte de los impactados.

\subsection{Antes: “Allá viene otro proyecto hidroeléctrico"}

La cuenca del río Porce viene siendo modificada desde la década de 1960 para la generación de energía hidroeléctrica (Vélez, et al, 2006). Este proceso ha dejado tras de sí un importante número de desplazados e impactos ambientales. Pero, ¿cómo reaccionó la población al enterarse de que otra hidroeléctrica sería construida en su 
territorio? En esta sección se presentan las percepciones de algunos pobladores.

En la localidad de El Limón, en el municipio de Anorí, uno de los pobladores de la zona supo, a través de la emisora radial del municipio vecino de Amalfi, que un nuevo proyecto hidroeléctrico llegaría. Se trataba de un anuncio que difundía la "declaratoria de utilidad pública", en 2003; en este se informaba que "quedaba congelado todo negocio de tierras en la región" y que EPM compraría las tierras para el proyecto. En el momento menos esperado, se dieron cuenta de que las comisiones llegaban a la zona para hacer levantamientos topográficos $\mathrm{y}$ censos, en los que les preguntaban por su actividad económica, vivienda, edades, número de hijos, etc. Sin embargo, algunos pobladores tradicionales de la región identifican cómo el censo inicial habría comenzado en la década de 1990. Otra habitante relata las reacciones de la población en los siguientes términos:

Se ponían contentos los que no eran de aquí, porque volvían para sus tierras con dinero [...] de la zona éramos pocos, los que se llevaron la plata eran de otras partes [...] Vivir en el río es muy bonito porque no nos falta la platica, hasta los más chiquitos tenían plata. [Sobre la salida de la margen del río]: En esa época que ya teníamos la adesa en medio de la gente [...] se alejan los amigos de uno, no vuelven. [Y cuando supo del proyecto]: para mí se juntó el cielo con la tierra, de ahí en adelante estuve aburrida hasta la negociación, ya cuando las casas estuvieron listas me animé porque veníamos para casa propia, porque venía para lo mío.
Simultáneamente, en otras localidades de la cuenca, otras familias y pobladores recibían también la noticia del nuevo proyecto; algunos con miedo, otros con desilusión y otros con optimismo, como se evidencia en las siguientes respuestas a la pregunta de cómo percibieron la llegada de Porce III.

\section{[...] Angustia, yo no me puse contenta,} porque nos iban a quitar el sustento, porque allá en Puente Acacias, gracias a Dios, cuando no se podía hacer barequeo pescábamos, nos inventábamos la comida, ya fuera con oro, con pesca [...] la vida era más fácil que aquí [...]. (Reasentada ${ }^{2}$ )

\section{$[\ldots]$}

Es muy difícil uno acostumbrarse a vivir de otra cosa [...] cuando nos dijeron que teníamos que salir fue duro, cuando no dijeron, es ya, tiene que salir [...] Los que no eran de allá se ponían contentos, a los que éramos de allá nos dio duro. (Pareja de reasentados)

Algunos reasentados manifestaron cómo durante el censo de población solo se les permitió informar una actividad principal y no todas las actividades productivas de la familia, lo que los obligaba a decidirse por aquella a la que más se dedicaban. Esto habría resultado en, por ejemplo, que las actividades domésticas productivas de las amas de casa no hubieran sido reconocidas, y en que rentas de extracción artesanal de oro no fueran reconocidas.

2 Es un término que no aparece en el diccionario de la lengua española. Es usado por la comunidad para significar un estado de adaptación. Algunos pobladores lo definen con ejemplos: "Adesar un animal y traerlo para que se adapte a la finca" (reasentada 3). 


\subsection{Durante: entre lo permitido y lo subrepticio}

Nos apoyamos en esta sección en un trabajo desarrollado en Muñoz (2015), en el cual analizamos, a partir de las manifestaciones críticas de la población, las formas de violencia en la construcción de la central hidroeléctrica Porce III, según estuvieran contenidas en prácticas institucionalizadas o no institucionalizadas.

\subsubsection{Críticas a lo institucionalizado}

Entendemos por prácticas institucionalizadas aquellas que están aprobadas o avaladas por el Estado dentro del proceso de licenciamiento ambiental. Estas se caracterizarían por lo siguiente: 1 . ser de conocimiento de todos los actores; 2. ser legales, en la medida en que el Estado las avala;
3. implicar una obligatoriedad para las partes. Los principales mecanismos o instrumentos instituidos para regular la interacción entre empresa y comunidades son: 1 . los contratos de reasentamiento; 2. el manual de valores unitarios; 3. el plan de gestión social; y 4. el plan de formación integral. Asociadas con las prácticas en la aplicación de esos instrumentos, identificábamos formas de violencia simbólica y epistemológica, como se expone a continuación.

\subsubsection{Críticas a la violencia simbólica}

La violencia simbólica (Bourdieu, 2013) sería aquella que es difícil de percibir, pues existen unos mecanismos para que ella pueda ser ejercida con apariencia de naturalidad y no como una forma de violencia (tabla 1).

Tabla 1. Formas de violencia simbólica

\begin{tabular}{|l|l|l|l|l|}
\hline & Actor & \multicolumn{1}{|c|}{ Práctica } & \multicolumn{1}{c|}{ Forma de violencia } & \multicolumn{1}{c|}{ Manifestaciones críticas } \\
\hline $\mathbf{1}$ & Estado & $\begin{array}{l}\text { "Declaratoria } \\
\text { de utilidad } \\
\text { pública". }\end{array}$ & $\begin{array}{l}\text { Es la primera y más amplia forma } \\
\text { de violencia simbólica. En esta } \\
\text { práctica se obliga a un grupo de } \\
\text { personas a abandonar su territorio } \\
\text { y a suspender su relación } \\
\text { sociocultural con ese territorio, } \\
\text { bajo la justificación de estar } \\
\text { priorizando un interés general } \\
\text { sobre el interés particular. }\end{array}$ & $\begin{array}{l}\text { Un poblador citado en la sección } \\
\text { anterior afirmaba: "Si el gobierno } \\
\text { necesita eso, tenemos que salir } \\
\text { a las buenas o a las malas" } \\
\text { (reasentado 1). }\end{array}$ \\
\hline 2 & Empresa & $\begin{array}{l}\text { Conversión } \\
\text { de } \\
\text { impactos y } \\
\text { afectaciones } \\
\text { en costos } \\
\text { monetarios. }\end{array}$ & $\begin{array}{l}\text { La combinación de mecanismos } \\
\text { e instrumentos de cálculo de } \\
\text { indemnizaciones (manual de } \\
\text { valores unitarios, contratos de } \\
\text { reasentamiento) obliga a que tanto } \\
\text { las afectaciones materiales como } \\
\text { las inmateriales sean convertidas } \\
\text { en cantidades monetarias (más } \\
\text { del 70 \% de la población afectada } \\
\text { fue compensada en dinero). }\end{array}$ & $\begin{array}{l}\text { "Yo creía que al construir un } \\
\text { proyecto con todos los derechos, } \\
\text { yo no necesitaba negociar, sino } \\
\text { que ellos sabían qué me tenían } \\
\text { conmigo" (reasentado 4). } \\
\text { "En esa época que ya teníamos la } \\
\text { adesa en medio de la gente [...] } \\
\text { se alejan los amigos de uno, no } \\
\text { vuelven" (reasentada 1). }\end{array}$ \\
\hline
\end{tabular}




\begin{tabular}{|c|c|c|c|c|}
\hline & Actor & Práctica & Forma de violencia & Manifestaciones críticas \\
\hline 3 & Empresa & $\begin{array}{l}\text { Desincentivo } \\
\text { a la } \\
\text { búsqueda de } \\
\text { asesorías o } \\
\text { alianzas para } \\
\text { la defensa de } \\
\text { derechos. }\end{array}$ & $\begin{array}{l}\text { La empresa recurre a su } \\
\text { reputación de empresa ambiental } \\
\text { y socialmente responsable para } \\
\text { convencer a los impactados } \\
\text { de no asesorarse de terceros } \\
\text { para negociar con la empresa. } \\
\text { Se recurre a la confianza en la } \\
\text { "virtud" de la empresa. }\end{array}$ & $\begin{array}{l}\text { Dos pobladores entrevistados } \\
\text { coincidieron en relatar, por } \\
\text { ejemplo, cómo la empresa les } \\
\text { manifestó que no era necesario } \\
\text { llevar otros representantes o } \\
\text { abogados; que la empresa les } \\
\text { iría a respetar la actividad que } \\
\text { tenían. }\end{array}$ \\
\hline
\end{tabular}

Fuente: Adaptado de Muñoz (2015).

\subsubsection{Críticas a la violencia epistemológica}

Como violencia epistemológica entendemos el tipo de violencia que se desprende del uso de ciertos conocimientos o saberes que pretenden imponerse sobre otros (tabla 2).

Tabla 2. Formas de violencia epistemológica

\begin{tabular}{|c|c|c|c|c|}
\hline & Actor & Práctica & Forma de violencia & Manifestaciones críticas \\
\hline 1 & Empresa & $\begin{array}{l}\text { Definición } \\
\text { de impactos } \\
\text { desde el } \\
\text { punto } \\
\text { de vista } \\
\text { técnico de la } \\
\text { empresa. }\end{array}$ & $\begin{array}{l}\text { Para las empresas, los verdaderos } \\
\text { impactos son aquellos definidos, } \\
\text { delimitados y evaluados desde } \\
\text { los estudios de impacto ambiental } \\
\text { (netamente técnicos y elaborados } \\
\text { sin participación real de las } \\
\text { comunidades impactadas). Así, } \\
\text { muchos de los argumentos de } \\
\text { las comunidades, basados en } \\
\text { sus saberes tradicionales, son } \\
\text { ignorados por las empresas. }\end{array}$ & $\begin{array}{l}\text { Sobre las consecuencias } \\
\text { ambientales, la población asocia } \\
\text { la presencia de los embalses y la } \\
\text { aparición de plagas. Tal es el caso } \\
\text { de un cierto tipo de mosquito } \\
\text { que pica las ubres de las vacas, lo } \\
\text { que acarrea pérdidas económicas } \\
\text { a los campesinos. La población } \\
\text { también denuncia un "cambio } \\
\text { climático" experimentado por } \\
\text { árboles frutales y cultivos, por } \\
\text { exceso de humedad, proveniente } \\
\text { de los embalses. Según ellos, este } \\
\text { problema ha sido investigado } \\
\text { por la empresa, pero esta niega la } \\
\text { causalidad. }\end{array}$ \\
\hline 2 & Empresa & $\begin{array}{l}\text { Negociación } \\
\text { en ambientes } \\
\text { de } \\
\text { desigualdad }\end{array}$ & $\begin{array}{l}\text { Violencia ejercida en ambientes } \\
\text { de negociación intimidantes, en } \\
\text { el que un grupo de profesionales } \\
\text { de diversas disciplinas se sienta } \\
\text { a negociar con una familia o } \\
\text { persona impactada. }\end{array}$ & $\begin{array}{l}\text { "Entonces nos citaban en una } \\
\text { fecha específica, más o menos } \\
\text { hasta } 10 \text { personas, estaban los } \\
\text { de medio ambiente, psicólogos, } \\
\text { abogados negociadores, pero no } \\
\text { el representante de la vereda" } \\
\text { (reasentado 4). }\end{array}$ \\
\hline
\end{tabular}

Fuente: Adaptado de Muñoz (2015). 


\subsubsection{Críticas a lo no institucionalizado}

A diferencia de las prácticas institucionalizadas, las no institucionalizadas no se encuentran consignadas en ningún documento oficial y tampoco han sido socializadas como reglas del juego válidas. Por esta razón, su ocurrencia es generalmente subrepticia. Las formas de violencia contenidas en las prácticas no institucionalizadas se caracterizan por constituir fuerzas o formas de poder que les sirven a las empresas para alcanzar sus objetivos en el corto plazo, y que no son reconocidas como legítimas (tabla 3).

Tabla 3. Formas de violencia en prácticas no institucionalizadas

\begin{tabular}{|c|c|c|c|c|}
\hline & Actor & Práctica & Forma de violencia & Manifestaciones críticas \\
\hline 1 & Empresa & $\begin{array}{l}\text { Monopolio de } \\
\text { la información, } \\
\text { entrega de } \\
\text { información } \\
\text { insuficiente, } \\
\text { parcial o, } \\
\text { en algunas } \\
\text { ocasiones, } \\
\text { falsa. }\end{array}$ & $\begin{array}{l}\text { Información inicial } \\
\text { insuficiente sobre las medidas } \\
\text { de restitución hizo que } \\
\text { muchas de las familias, al no } \\
\text { tener claro cuáles serían sus } \\
\text { opciones al dejar su territorio, } \\
\text { aceptaran compensaciones } \\
\text { en dinero, con lo que } \\
\text { asumieron un mayor riesgo } \\
\text { de empobrecimiento, que } \\
\text { significó menor costo para } \\
\text { la empresa, al no compensar } \\
\text { con tierra, vivienda y } \\
\text { acompañamiento a un } \\
\text { proyecto económico. }\end{array}$ & $\begin{array}{l}\text { “Allí no se hablaba de derechos de } \\
\text { nadie, nosotros no valorábamos } \\
\text { derechos de actividades [...] } \\
\text { teníamos un más o menos, pero } \\
\text { no teníamos la certeza de esos } \\
\text { ingresos [...]" (reasentado } 4 \text { ). } \\
\text { “Cuando negociaron con } \\
\text { nosotros, los primeros, solo había } \\
\text { compra directa. ¿Yo qué podía } \\
\text { decir cuánto podía valer mi } \\
\text { propiedad si no sabía pa' dónde } \\
\text { me tenía que ir yo?" (reasentado } \\
\text { 4). }\end{array}$ \\
\hline 2 & $\begin{array}{l}\text { Uso del } \\
\text { poder } \\
\text { económico } \\
\text { para } \\
\text { cooptar } \\
\text { líderes. }\end{array}$ & $\begin{array}{l}\text { Conversión } \\
\text { de impactos } \\
\text { y afectaciones } \\
\text { en costos } \\
\text { monetarios. }\end{array}$ & $\begin{array}{l}\text { La combinación } \\
\text { de mecanismos e } \\
\text { instrumentos de cálculo de } \\
\text { indemnizaciones (manual de } \\
\text { valores unitarios, contratos } \\
\text { de reasentamiento) obliga } \\
\text { a que tanto las afectaciones } \\
\text { materiales como las } \\
\text { inmateriales sean convertidas } \\
\text { en cantidades monetarias } \\
\text { (más del } 70 \% \text { de la población } \\
\text { afectada fue compensada en } \\
\text { dinero). }\end{array}$ & $\begin{array}{l}\text { "[...] [al representante de la } \\
\text { comunidad ante la comisión } \\
\text { tripartita] le metieron la mano al } \\
\text { bolsillo" (reasentado 5). } \\
\text { "[...] [el representante de la } \\
\text { comunidad ante la comisión } \\
\text { tripartita] manejaba mucha } \\
\text { influencia en la cuenca [...] } \\
\text { Él ayudó con proyectos de } \\
\text { electrificación en la vereda, etc. } \\
\text { El hombre fue buena gente, pero } \\
\text { tiene sus cosas que se tragó solito" } \\
\text { (reasentado 6, cursivas nuestras). }\end{array}$ \\
\hline 3 & Empresa & $\begin{array}{l}\text { Uso del poder } \\
\text { económico } \\
\text { para } \\
\text { acelerar las } \\
\text { negociaciones. }\end{array}$ & $\begin{array}{l}\text { Los espacios de negociación } \\
\text { individualizada se } \\
\text { configuraron en un escenario } \\
\text { para el uso del poder } \\
\text { económico en favor de la } \\
\text { rápida negociación de las } \\
\text { indemnizaciones. }\end{array}$ & $\begin{array}{l}\text { “[...] compraban las personas con } \\
\text { atenciones, almuerzos, paseos, } \\
\text { etc., pero a los que negociaron de } \\
\text { último les fue mejor" (reasentada } \\
\text { 1). } \\
\text { “[...] y me decían: '¿vos querés } \\
\text { más tierra?'; y entonces me daban } \\
{[\ldots] \text { me dieron otra tierra, por }} \\
\text { cualquier cosita me daban }[. . .] \text { ” } \\
\text { (reasentado } 2 \text { ). }\end{array}$ \\
\hline
\end{tabular}




\begin{tabular}{|c|c|c|c|c|}
\hline & Actor & Práctica & Forma de violencia & Manifestaciones críticas \\
\hline 3 & Empresa & $\begin{array}{l}\text { Uso del poder } \\
\text { económico } \\
\text { para } \\
\text { acelerar las } \\
\text { negociaciones. }\end{array}$ & $\begin{array}{l}\text { Fue evidente que personas } \\
\text { que tenían los mismos } \\
\text { derechos accedieron a montos } \\
\text { variables de negociación, } \\
\text { en la medida en que se } \\
\text { resistían a recibir el primer } \\
\text { ofrecimiento que les hacían. }\end{array}$ & $\begin{array}{l}\text { Fue evidente que personas que } \\
\text { tenían los mismos derechos } \\
\text { accedieron a montos variables } \\
\text { de negociación, en la medida en } \\
\text { que se resistían a recibir el primer } \\
\text { ofrecimiento que les hacían. }\end{array}$ \\
\hline 4 & Empresa & $\begin{array}{l}\text { Criminalización } \\
\text { de la protesta. }\end{array}$ & $\begin{array}{l}\text { En los momentos en que las } \\
\text { comunidades se manifiestan, } \\
\text { incluso pacíficamente, } \\
\text { contra la empresa, y en que } \\
\text { realizan bloqueos al paso de } \\
\text { la maquinaria, por ejemplo, } \\
\text { la empresa acciona la fuerza } \\
\text { pública para desarticular } \\
\text { esas manifestaciones. Se } \\
\text { han presentado casos en } \\
\text { que llevan a los líderes de } \\
\text { las protestas a las estaciones } \\
\text { de policía, obviamente para } \\
\text { intimidar al resto de los } \\
\text { manifestantes. }\end{array}$ & $\begin{array}{l}\text { “Nosotros terminamos [las } \\
\text { protestas] [...] Cuando menos } \\
\text { pensé llegaron dos tanquetas } \\
\text { [...] me dijeron 'súbase aquí'. } \\
\text { Entonces nos llevaron [...] Por allá } \\
\text { se arrimó uno y me dijo: 'no ve } \\
\text { señor, por rebelde vea lo que les } \\
\text { va a pasar' [...] y le dije: ¿rebelde? } \\
\text { Yo no he matado a nadie, yo estoy } \\
\text { es reclamando un derecho. Nos } \\
\text { dijeron: 'nosotros somos de la } \\
\text { SIJIN, nos mandaron por ustedes'. } \\
\text { Me dijeron que por poquito esto } \\
\text { me iba a dar seis años de prisión, } \\
\text { y le dije, pueden ser } 20 \text { porque } \\
\text { lo que estoy haciendo es de todo } \\
\text { corazón [...]. Como a la una de la } \\
\text { mañana cogieron una lista grande } \\
\text { y yo no estaba en esa lista [...] } \\
\text { 'venga firme allí para que se vaya } \\
\text { para la casa"”' (reasentado } 4 \text { ). }\end{array}$ \\
\hline 5 & Empresa & $\begin{array}{l}\text { Desconoci- } \\
\text { miento de las } \\
\text { mujeres en } \\
\text { las primeras } \\
\text { fases de las } \\
\text { negociaciones. }\end{array}$ & $\begin{array}{l}\text { En este caso, se presenta una } \\
\text { violencia contra un grupo } \\
\text { poblacional, al discriminarlo } \\
\text { por su género y desconocer } \\
\text { que se trataba de familias en } \\
\text { las que el patrimonio familiar } \\
\text { debía ser protegido. }\end{array}$ & $\begin{array}{l}\text { "EPM vino a reconocer el } \\
\text { patrimonio familiar, que en la } \\
\text { familia tenían derechos los dos, ya } \\
\text { tarde, buscaban al hombre para } \\
\text { negociar y no a la mujer sabiendo } \\
\text { que tenía tres o cuatro hijos al } \\
\text { lado, eso causó problemas, de que } \\
\text { fue el hombre que dispuso de la } \\
\text { plata y por eso hoy hay hogares } \\
\text { desbaratados" (reasentado } 4 \text { ). }\end{array}$ \\
\hline
\end{tabular}

Fuente: Adaptado de Muñoz (2015). 


\subsection{Después: "Si hubiéramos comenzado antes"}

Para la época del trabajo de campo que informa esta investigación, la población llevaba entre cuatro y cinco años de haber sido reasentada. Con ese tiempo de adaptación, es posible identificar su posición crítica retrospectiva respecto al proceso de reasentamiento.

Identificamos un conjunto de críticas de la población al cambio ocasionado por el reasentamiento y al desarrollo de los "proyectos productivos" agropecuarios o de comercio y servicios. Los primeros consistieron en la disposición de un terreno para producir café, cacao, frutales, hortalizas y/o criar ganado. Los segundos consistían en el establecimiento de un negocio de comercio o servicios en las zonas urbanas de los municipios vecinos. En ambos casos, se restituía la vivienda. Aunque los resultados sean diversos en términos de adaptación, lo que es constante en las manifestaciones de los entrevistados son las problematizaciones al proceso y sus resultados.

Una de las reasentadas entrevistadas coincide con otros pobladores en problematizar la dificultad para obtener ingresos suficientes de la actividad agropecuaria, problemática que llevó a varios de los reasentados a vender total o parcialmente los terrenos recibidos. Como causa de esa dificultad, muchos pobladores identifican el retraso en la preparación de las tierras para la producción de cacao y leche, actividades que pasaron a representar para ellos la principal fuente de ingreso. Para explicar lo anterior, uno de los reasentados afirma que ese retraso se debió a que muchos recursos se invirtieron en ensayos productivos cuando los terrenos aún no estaban aptos. Por ejemplo, no se podía mantener el ganado adecuadamente por falta de cercos.

Así, las familias alcanzaron volúmenes muy diferentes en la producción de leche y cacao con las consiguientes diferencias en generación de ingresos, por un conjunto de causas, que ellos identifican con los siguientes elementos: la demora en la inversión para alistar las tierras; la necesidad de hacer inversiones significativas en herramientas y equipos, lo que afectó el presupuesto de las familias; la necesidad de sobrevivir del dinero de la indemnización o de endeudarse mientras llegaban las cosechas y la producción; las diferencias en los montos de las indemnizaciones, etc.

Uno de los entrevistados, cuya actividad anterior al desplazamiento era la minería, manifestaba lo siguiente, incluyendo una autocrítica y autoresponsabilizándose por la falta de éxito en las nuevas condiciones de vida impuestas por la empresa:

Aquí faltó acompañamiento, que estas parcelas estuvieran produciendo, porque por ejemplo el cacao se demora cuatro años, la yuca y el plátano sí dan más rápido, pero no hay quien los compre. Faltó más seguimiento técnico $[. .$. Para un proyecto de estos se necesita mucho acompañamiento, porque es más fácil con gente que sea del campo, nosotros somos unos derrochadores, no sabemos ahorrar, etc. [...] Sabemos es gastar.

Otros dos entrevistados coincidían en señalar deficiencias en el proceso de acompañamiento económico de las familias reasentadas, pues la empresa habría contratado 
profesionales con poco conocimiento del cultivo de cacao, situación que habría generado una pérdida de recursos de los presupuestos familiares en ensayos iniciales.

Una joven, hija de una familia reasentada, con 18 años para el momento de la entrevista, y quien se desempeñaba en ese entonces como secretaria de la asociación de productores de leche establecida para la comercialización, se posicionaba críticamente en relación con la medida de indemnización en dinero, al manifestar que con ella las familias perdieron su capital y fuentes de ingresos. Igualmente, criticaba la forma como se hicieron las inversiones y los retrasos; específicamente, habla del caso de su familia, que en ese entonces estaba considerando vender la finca para comprar propiedades en la ciudad y arrendarlas, como hicieron algunos de los vecinos. Según ella, su padre nunca se sintió muy bien con el cambio de actividad, de minero a productor agropecuario. $\mathrm{Al}$ respecto, su padre manifestaba:

Nosotros optamos por proyecto económico para conservar la adesa [...] Cuando uno no está acostumbrado a lidiar con una cosa no avanza, yo me imaginaba que si uno salía de un lugar era para hacer lo que uno sabe hacer [...] las fincas sí dan, pero con el tiempo [...] allá éramos muy humildes[,] pero no nos faltaba nada, estábamos tranquilos. Aquí yo me he sentido hasta estresado por no tener plata [...] la salvación es el hijo que está trabajando [...] [en un contrato como guardabosques con la empresa].

Al llevar más a fondo la crítica, el mismo poblador entrevistado habla de lo que él considera que habría sido una mejor compensación para los desplazados: "Por donde la empresa pasa la ganancia es sólo para ellos, lo que queda son historias. Ellos nunca pierden porque pagan su deuda con los bancos y la mina [refiriéndose a la central hidroeléctrica] sigue produciendo [...] ¿Por qué la empresa no nos da una pensión? Una empresa que recibe tanta plata".

Otro de los reasentados, cuenta que él se acogió a un proyecto agropecuario porque sabía de agricultura: "Los que eran mineros, mineros, fracasaron [...]", afirma. En relación con los proyectos agropecuarios y el cambio de vida de mineros a agricultores, afirma que la entrega de tierra en sí no garantiza el sostenimiento de una familia, e insiste en que para vivir de la agricultura es necesario "planear los trabajos". En este sentido, reconoce que ahora está obteniendo beneficios de la plantación de cacao, que, según él, debió ser proyectada desde el comienzo. Y agrega: “[...] hubo un cada modelo, pero no hubo un proyecto agropecuario modelo [...]".

Finalmente, y en el mismo sentido, otro de los reasentados concluye: "Yo estoy contento porque mi proyecto fue grande [producto de una mayor indemnización], si hubiera sido pequeño [como el de la mayoría de las familias reasentadas] no alcanzaría, tal vez si la empresa entregara un proyecto produciendo $[\ldots]^{\prime \prime}$.

\subsection{Las justificaciones de las críticas de la población}

En esta sección nos aproximamos, desde lo que algunos denominan sociología de la 
justificación $n^{3}$, a la comprensión de las formas de crítica ante las violencias del contexto estudiado.

A continuación se presenta un análisis preliminar de la compilación de las críticas de la población impactada, sin llegar al grado de identificación de los órdenes de justificación o cités (Boltanski, 2014), lo que requeriría un trabajo de mayor profundidad. Las informaciones recolectadas en las entrevistas evidencian una rica variedad de formas de crítica de la población o problematizaciones a la implementación de la central, al desplazamiento, al proceso de reasentamiento y a la "gestión social". En el ejercicio de recopilación de las críticas de Muñoz (2016), se observan por lo menos 15 argumentos de justificación: autonomía sobre la propiedad, bien común, cohesión o sentido de comunidad, conservación de la propiedad, conservación de las formas de vida, estabilidad moral-emocional, estabilidad económica, igualdad (entre los indemnizados, igualdad de género), libre acceso a la información, libre elección, derecho a la protesta, honestidad/transparencia, rechazo a la monetización de los derechos, compromiso de cumplimiento de los "contratos de reasentamiento" y reconocimiento de derechos.

Es posible identificar tres ámbitos de agrupamiento de las formas de crítica: los efectos de la central, las formas de acción de la empresa y los procedimientos y prácticas de la "gestión social".

En el primer ámbito están las críticas dirigidas a la construcción de la central, como es el caso de la problematización de los efectos

3 Para una aplicación más detallada de esta propuesta sociológica de Boltanski, al análisis de la interacción entre capitalismo y crítica evidenciada en la "gestión social" de Porce III, véase Muñoz (2015). sobre la estabilidad emocional de la población, en función de la incertidumbre sobre el futuro; el miedo a la pérdida de la adaptación al territorio, que los pobladores llaman la adesa; a la desestabilización económica de las familias; a la fragmentación de los lazos comunitarios por el desplazamiento; a la llegada de personas externas, que ejerzan presión sobre los recursos del territorio; a la generación de miseria, etc. Critican, también, el trato diferenciado recibido por parte del Estado, pues haber sido indemnizados por la empresa les acarreó obligaciones tributarias y pérdida de subsidios públicos. Finalmente, se encuentran las críticas a la lógica de cálculo de las indemnizaciones, en la que todo llevaba a valores monetarios. Este conjunto de críticas, en la medida en que cuestiona la legitimidad de la central como detonadora de cambios y afectaciones a la población, podría ser entendido como un ejercicio de lo que Boltanski y Chiapello (2002) denominan crítica radical, aquella que cuestiona los fundamentos de los formatos establecidos o pruebas, como los denominan los autores.

En el ámbito de las prácticas de los funcionarios de la "gestión social" se encuentran las críticas al desconocimiento de derechos en primera instancia, pues, conforme había resistencia de las familias, se iban aumentando las indemnizaciones, lo que generó un tratamiento desigual a las personas impactadas. Críticas al tratamiento desigual según el género; a la desarticulación de las protestas mediante el uso de la fuerza pública; a la cooptación de líderes mediante la concesión de beneficios; a la falta de transparencia, y al ejercicio de presiones para la negociación acelerada. Estas críticas constituyen problematizaciones de las prácticas no 
institucionalizadas, que Boltanski y Chiapello (2002) denominan desplazamientos.

Finalmente, se evidencian críticas a lo institucionalizado por la "gestión social", ya fuera porque la población no lo juzgaba adecuado o porque aquello que estaba establecido en los procedimientos y normas no fue cumplido. En el primer caso se encuentran las críticas al hecho de tener que negociar los derechos sin ninguna preparación, sin mediadores y con un grupo de profesionales de la empresa expertos en ese tipo de procedimientos; críticas a la imposibilidad o dificultad para obtener ingresos aceptables con los proyectos productivos, y la nueva sujeción al pago de impuestos y servicios públicos. En el segundo caso, hubo críticas al retraso en el montaje de los proyectos productivos; a la demora en la entrega de los títulos de propiedad de las tierras; a la falta de preparación de los funcionarios asesores para el montaje de los proyectos, $\mathrm{y}$ al incumplimiento de los contratos de reasentamiento, en su propósito de "restituir las condiciones de vida". Incluso, en este conjunto de críticas estuvo la observación de uno de los reasentados, al cuestionar por qué la empresa no entregaba una renta vitalicia a los impactados. Estas problematizaciones de los formatos de la "gestión social" serían, en la misma clave analítica de Boltanski y Chiapello, críticas de tipo correctivo, aquellas que pretenden aumentar el grado de justicia de lo instituido.

\section{Formas de RESISTENCIA}

En esta sección compilamos algunas prácticas identificadas en las entrevistas con la población impactada, que consideramos son formas de resistencia o contraconductas frente a lo dispuesto por las prácticas y mecanismos de la "gestión social". Agrupamos esas resistencias en tres grupos: resistencias colectivas para garantizar derechos, resistencias individuales en las negociaciones y resistencias al cumplimiento de lo establecido por los procedimientos, planes y contratos.

\subsection{Las resistencias colectivas}

Una de las acciones emprendidas por la comunidad cuando llegó el proyecto al territorio fueron las protestas en vía pública. Conviene señalar que el avance de la empresa por el territorio y la intervención con maquinaria se dio de forma concomitante con las "negociaciones" de los terrenos que el proyecto iba necesitando para construir vías de acceso e instalaciones.

Según uno de los líderes comunitarios entrevistados, las protestas surgieron de la inconformidad de la población por diversos motivos: "Unos protestábamos porque nos sentíamos engañados, otros porque no les reconocían derechos, otros porque los hijos no habían sido incluidos como afectados en su actividad económica y otros porque estaban perdiendo su actividad económica".

Otra razón común para la protesta era que los pobladores comenzaron a notar el aumento de los precios de los materiales de construcción, por la presencia de la empresa y sus operaciones en la zona.

Ante esta situación, la comunidad se asoció bajo la forma de un comité, con representantes de las localidades impactadas, para hacer las protestas; también, se articuló con algunos ámbitos estatales para dar visibilidad a sus reivindicaciones. Según el mismo 
líder entrevistado, por medio de esta forma de asociación consiguieron coordinar los bloqueos de vías, hacer comisiones a Medellín para reunirse con los concejales, quienes, dicho sea de paso, tienen la función de control sobre EPM, por ser una empresa estatal del municipio. Se reunieron, igualmente, con representantes de la Asamblea del Departamento de Antioquia para exponer sus reclamos e inconformidades con el proceso de desplazamiento. Consiguieron, también, articularse con el ministerio público de uno de los municipios del área de influencia para recibir asesoría. Este representante se presentaría posteriormente como candidato a la alcaldía de dicho municipio, con el apoyo de las comunidades impactadas.

Este líder comunitario cuenta que por haber estado a la cabeza de las protestas en su localidad, después de negociar su propia indemnización, la empresa lo descalificaba como representante de la comunidad y se negaba a atender las reivindicaciones en las cuales él apareciera como firmante. El carácter de confrontación argumentativa de este líder derivada de su experiencia como concejal de su municipio, lo que le permitía ejercer presión sobre la empresa, al conocer el funcionamiento de los asuntos públicos, tanto presupuestales, como de control político al que aquella estaba sometida.

Como resultado de la última protesta, que duró más de 20 días, y congregó a más de 700 personas en las diferentes localidades, la empresa se dispuso a analizar varios casos y, según cuenta el entrevistado, reconocía que la compra directa, es decir, la inseminación en dinero, no habría salido bien, y que por tanto era necesario pensar en otras formas de compensación. De allí habrían salido otras opciones de restitución de condiciones de vida, por medio de proyectos productivos en zonas más alejadas del embalse.

La respuesta de la empresa después de las protestas fue esperar que se calmaran los ánimos para comenzar a llamar a los líderes, con el ánimo de negociar primero con ellos. Según cuenta este líder, ello hizo que muchos de esos representantes se retiraran y que se perdiera la fuerza de las protestas.

En otra entrevista, uno de los impactados cuenta cómo, por medio de las protestas y bloqueos, habrían conseguido que la empresa reubicara temporalmente a familias que estaban en riesgo por causa de la construcción de las vías del proyecto, así como acelerar la compra de los terrenos para ubicar a las familias al lado del embalse, que se aprobara la medida de relocalización (consistente en reasentar a las familias en municipios por fuera del área del proyecto) y se hiciera un reajuste del $20 \%$ en el valor de los proyectos económicos recibidos como compensación.

\subsection{Las resistencias individuales}

Algunos ejemplos de resistencia individual pueden observarse durante el llamado proceso de negociación. En términos formales, el proceso de indemnización estuvo definido por el Manual de Valores Unitarios, un instrumento elaborado por una comisión tripartita entre Estado, empresa y comunidades, mediante el cual se establecía el valor de los bienes objeto de compensación. Sin embargo, la empresa configuró un proceso de regateo, en el que, dependiendo de la resistencia que cada familia o persona impactada presentara, esta obtenía términos 
variables en su indemnización, como aparece documentado en Muñoz (2016).

La variabilidad de los resultados en función de la resistencia de las familias puede ser identificada en los testimonios de algunos pobladores entrevistados. Uno de ellos cuenta como, si la persona estaba con prisa en la negociación, le daban un proyecto de menor valor, pero si esperaba más, obtenía mejores resultados: "En muy pocos casos, cuando hubo resistencia de la persona o familia que estaba en la negociación, la empresa entregó valores mayores", afirma. Y explica su caso, al comentar que la primera oferta que recibió fue de 25 millones de pesos en dinero, pero el resultado final fue una indemnización por 57 millones de pesos, que incluía un proyecto agropecuario y la restitución de sus condiciones de vida. $Y$ agrega: "Con ese proceso no sólo yo, sino la mayoría de la gente nos sentimos violados en nuestros derechos, todo bien que sacamos beneficios, pero, no nos indemnizaron como nos tenían que indemnizar [...] no hubo criterios uniformes de indemnización y negociación".

Otro de los pobladores señala cómo, por medio de su resistencia a aceptar la primera oferta, logró otros beneficios: “¿Sabe qué me decía [la coordinadora de la Gestión Social] en las reuniones?: 'No, no, no, no calentés las cosas [...] vos vivís muy bien [...] lo tuyo nosotros lo arreglamos, no te pongás a calentar esta gente', y me decían: ‘vos querés más tierra?'; y entonces me daban [...] me dieron otra tierra, por cualquier cosita me daban $[\ldots]^{\prime \prime}$.

En otro relato, un poblador reasentado, reconocido y próspero comerciante de la zona cuenta cómo su negociación fue muy atípica. La coordinadora de la "gestión social" le habría ofrecido opciones muy informalmente, situación que califica como "extraña", lo que lo habría puesto a dudar sobre qué decisión tomar. Posteriormente, él acudió a otro funcionario de mayor rango, el cual frecuentaba su establecimiento comercial, y en diálogo con este consiguió beneficios que los demás funcionarios no le habían concedido.

Se evidencia, pues, cómo dependiendo de las habilidades de la persona en el proceso de "negociación" y su resistencia a aceptar lo ofrecido por los funcionarios de la empresa, los resultados finales fueron diferentes.

\subsection{Las resistencias al cumplimiento de lo establecido}

Después del traslado a los nuevos reasentamientos, otras prácticas de la población impactada pueden ser consideradas como formas de resistencia al dispositivo de la "gestión social". Presentamos a continuación algunos ejemplos relacionados con la omisión de recomendaciones recibidas y el incumplimiento de compromisos establecidos por ellos con los funcionarios de la empresa.

En el aspecto económico, por ejemplo, algunas familias dieron un uso diferente a los recursos que les eran entregados para el establecimiento de los proyectos productivos. Los recursos eran periódicamente entregados a las familias para la compra de insumos, herramientas, etc., pero en algunos casos, las familias definían otras prioridades, como vestido, muebles o electrodomésticos. Esta práctica muestra una resistencia al control presupuestal establecido desde los 
"contratos de reasentamiento" que tuvieron que firmar con la empresa.

Otro ejemplo de resistencia a lo dispuesto por el contrato se evidenció en el ejercicio de la actividad de minería tradicional, que algunos de los reasentados continuaron realizando en los terrenos de la "zona de influencia directa" del proyecto, contrario al compromiso adquirido por ellos en el mencionado contrato.

De igual forma, algunas recomendaciones de "manejo ambiental" de la finca fueron omitidas por algunas familias, que consideraban que, al acatarlas, estaban sacrificando parte de su tierra productiva, como era el caso de la recomendación de dejar franjas de protección sin cultivar en los cauces de las corrientes de agua. Cabe anotar que muchas de las prácticas que la "gestión social" quería modificar, por medio del programa de educación ambiental, son prácticas tradicionales de los campesinos en el país.

Finalmente, como consecuencia de los problemas de adaptación a las nuevas formas de vida, muchas familias optaron por incumplir lo firmado en el contrato, referente a mantener la propiedad sobre todo el terreno recibido.

Una mujer reasentada lo manifestaba en los siguientes términos: "Algunas personas vendieron los terrenos [restituidos] porque tenían necesidades [...] Mi esposo no está trabajando en la finca de nosotros por falta de plata, porque no tenemos cómo mantenernos, como dice él 'si yo tuviera con qué mantener la finca no vendería, le pondría entusiasmo', pero si resulta un negocio, tenemos que vender $[\ldots]^{\prime \prime}$.
Es importante también anotar que algunos de los terrenos vendidos no poseían aún los títulos de propiedad que la empresa debía entregar a las familias; sin embargo, algunas consiguieron efectuar la venta. Al momento del trabajo de campo, cinco años después de la entrega material de los terrenos a las familias, la mayoría de los títulos no habían sido entregados. Posiblemente se trató de una estrategia de la empresa para impedir la venta de tierras y garantizar el éxito del reasentamiento; sin embargo, esto podría configurar una violación del derecho de esas familias de disponer autónomamente de su patrimonio.

\section{LA DESCALIFICACIÓN DEL PODER COMO ELEMENTO DE CONTRACONDUCTA}

Creemos que las críticas de los impactados, en cuanto manifestaciones de conflicto con la forma como fueron conducidos en el proceso de reasentamiento, podrían considerarse expresiones de contraconducta o líneas de subjetivación. La siguiente afirmación de Foucault (2008) nos sugiere tal relación: "Me parece que la Edad Media desarrolló cinco formas principales de contraconductas que tienden, todas ellas, a redistribuir, a invertir, a anular, a descalificar parcial o totalmente el poder pastoral en la economía de la salvación, en la economía de la obediencia y en la economía de la verdad [...] que caracterizan, en mi opinión, el objetivo, el dominio de intervención del poder pastoral" (Foucault, 2008, p. 269) (Cursivas nuestras).

En esta cita observamos que la descalificación del orden establecido o de las disposiciones de las instituciones es un elemento de 
contraconducta, según lo entiende este autor. Más precisamente, él habla de la descalificación que las creencias escatológicas (como quinto elemento de esas contraconductas al poder pastoral $)^{4}$ hicieron del papel del pastor, al pregonar que el propio Dios estaba por llegar, con el objetivo de tornar innecesaria la intervención del pastor terrenal.

De forma análoga, observamos cómo un conjunto de las problematizaciones del dispositivo identificadas en la sección anterior descalifican funcionarios, procedimientos, prácticas, etc., todos ellos elementos del ejercicio del poder, que podríamos denominar poder gestionario de la "gestión social" descrita hasta aquí. En este punto, la identificación de las fuentes de justificación de las críticas de la población elaborada en la sección 1.4 nos sirve para alimentar el ejercicio genealógico de identificar la procedencia de estas como elementos de contraconducta del dispositivo.

Por ejemplo, en el conjunto de críticas que llamábamos radicales en la sección 1.4, se observa la reivindicación de la adesa, un término local compartido por los pobladores del territorio para indicar que la mina le ofrecía al minero una estabilidad económica, emocional y espacial. Estas críticas son externas a la forma de gobierno promovida por la "gestión social"; son, incluso, contrarias a la lógica de gestión que promueve en los impactados la capacidad de adaptación.

4 La descalificación del poder del pastor, junto con las prácticas de ascetismo, el establecimiento de formas comunitarias de organización, la mística y la escritura, serían formas de contraconducta al poder pastoral de la Edad Media identificadas por el autor. Para mayor información, véase la clase del $1^{\circ}$ de marzo de 1978, en Foucault (2008).
De la misma forma, problematizar la conversión de bienes y formas de vida en cantidades monetarias, impuesta por el proceso de cálculo de las indemnizaciones, comporta un cuestionamiento desde lógicas contrarias a la lógica de gestión, para la cual el mercado es el espacio por excelencia de la sociedad de los empresarios.

Los impactados descalificaron las prácticas no institucionalizadas de la empresa, mediante el rechazo del uso de diversas fuerzas, como la fuerza del dinero y la Fuerza Pública, para desarmar y desincentivar la unidad de los impactados. Nuevamente, la fuente de descalificación es externa y contraria a la lógica de gestión que promueve la autonomía de los individuos para manejar su destino.

Se observa cómo este tipo de crítica se apoya en elementos justificativos provenientes del mundo (Boltanski, 2014), por fuera de la realidad construida por el dispositivo de la "gestión social", como lo analiza este autor para las posibilidades de la crítica radical. Sin embargo, las descalificaciones de las prácticas agrupadas en lo que identificamos como críticas reformistas, se alimentaban de argumentos tomados de la propia lógica del mercado y la gestión. Reclamos por mayores valores de indemnización para garantizar mejores condiciones de vida después del desplazamiento; por la inversión oportuna para el montaje de los proyectos productivos; por el cumplimiento de los contratos de reasentamiento; y por mejor cualificación de los técnicos de la "gestión social", evidencian una incorporación de la lógica promovida por el dispositivo. En este caso, los actores se tomaron en serio la realidad construida por el dispositivo y cuestionaron 
el incumplimiento de lo establecido por los procedimientos instituidos.

\section{Conclusiones}

Aunque los dispositivos actúen promoviendo subjetividades o identidades, para buscar la producción de unas identificaciones determinadas (Dean, 2010), el éxito de ese proceso no está garantizado; al contrario, según algunos autores, hay evidencias de que las actividades de gobierno estarían predestinadas al fracaso. Así, Dean (2010, p. 85) habla de un "carácter contingentemente fracasado" de los programas de gobierno. Igualmente, Ferguson y Lohmann hablan de la repetida implantación de los programas de desarrollo rural en Lesoto, a pesar de que ellos fallaban sistemáticamente en alcanzar sus objetivos. En este último caso, los autores atribuyen el fracaso al hecho de que tales programas estuvieran basados en una construcción que guardaba poca semejanza con las "realidades prevalentes" (Ferguson \& Lohmann, 1994, p. 176). En el sentido antes expuesto, hay indicios del posible fracaso de la "gestión social" como forma de gobierno, por medio de la producción de sujetos civilizados, emprendedores y ambientalizados (Muñoz, 2016). Son evidencias de ello las problematizaciones, las críticas y las resistencias ofrecidas por la población impactada, que, como vimos en este trabajo, se oponían de diversas formas y con diversas estrategias discursivas y no discursivas a la asimilación de los lineamientos dados por la empresa, por medio de los instrumentos del proceso de reasentamiento.

Se evidenció, también, que las formas y los grados de resistencia fueron variables, según la habilidad comunicativa de los impactados para oponerse a los términos de las negociaciones y de las recomendaciones del proceso de acompañamiento de la "gestión social". Como es anotado por la población entrevistada, ese proceso de negociación individualizada generó también resultados variables en términos de restitución de condiciones e indemnización, lo que devino en procesos igualmente variables de adaptación a esas nuevas formas de vida. Cabe anotar que las trayectorias de vida de los impactados tampoco eran homogéneas, y algunos habían desarrollado disposiciones para adaptarse más fácilmente a lo que se esperaba de ellos en el proceso de reasentamiento.

Identificamos formas específicas de contraconducta de los habitantes impactados, que, por la vía de resistencias individuales y colectivas, buscaron anular o profanar las disposiciones de lo instituido por el proceso de reasentamiento, por las técnicas y lógicas de los instrumentos de gestión que los conducían, y las violencias que ellas encarnaban.

Igualmente, se identificó una variedad de manifestaciones críticas, las cuales, apoyadas en justificaciones traídas tanto de la lógica del propio dispositivo, como de otras lógicas externas a él, incluidas algunas que orientaban sus formas de vida ${ }^{5}$ antes del reasentamiento, expresaban un elemento de contraconducta: la descalificación de las formas de gobierno imperante.

5 Guedes (2011) desarrolla el argumento de cómo, por medio del análisis de las culturas populares, es posible identificar experiencias y saberes culturalmente acumulados, que, en situaciones límite, como las que implica el desplazamiento obligatorio, permiten a los impactados, por lo menos, hacer que las "vivencias sean menos traumáticas" (p. 439), para configurar así, pero no exclusivamente, una forma de resistencia. 
Estas evidencias de resistencia y crítica a las prácticas y técnicas de la "gestión social" ponen en cuestión la capacidad de los "expertos" para "transformar cuestiones de injusticia y distribución desigual de poder en cuestiones técnicas relativas a la mejor forma de organizar y gestionar regímenes de seguridad, empresas o personas", respondiendo a la duda que Miller y Rose (2012, p. 260) se plantean en ese sentido; lo cual nos anima al conocimiento y reconocimiento de estas formas y fuentes de resistencia y crítica, como un elemento importante para la articulación, en diversas escalas, de un movimiento crítico de las prácticas y efectos de la "gestión social" en grandes proyectos de infraestructura, como representantes de una visión de desarrollo que se implementa acompañada de nuevas formas de violencia y revictimización.

\section{REFERENCIAS}

Agamben, G. (2011). ¿Qué es un dispositivo? Sociológica, 26(73), 249-264.

Boltanski, L. (2014). De la crítica. Compendio de sociología de la emancipación. Madrid, España: Akal.

Boltanski, L., \& Chiapello, E. (2002). El nuevo espíritu del capitalismo. Madrid, España: Akal.

Boltanski, L., \& Thévenot, L. (1999). The sociology of critical capacity. European Journal of Social Theory, 2(3), 359-377.

Bourdieu, P. (2013). Las estrategias de la reproducción social. Buenos Aires, Argentina: Siglo Veintiuno.

Da Rocha, H. (2014). A Condição de Atingido por Barragem. En: I Seminário Internacional e III Seminário Nacional: Movimentos sociais, Participação e Democracia.
2010. Florianópolis. Recuperado de http://www.sociologia.ufsc.br/npms/ $\mathrm{mspd} / \mathrm{a} 023 . \mathrm{pdf}$

Dean, M. (2010). Governmentality. Power and rule in Modern Society. Londres, Inglaterra: Sage Publications Ltd.

Del Moral García, Á. (2009). De la crítica. Compendio de sociología de la emancipación. Revista de la Asociación de Sociología de la Educación, 8(2), 303-306.

Deleuze, G. (1991).'What is a dispositif?' En T. J. Armstrong (Ed.), Michel Foucault: Philosopher (pp. 159-68) Neva York, Estados Unidos: Harvester Wheatsheaf.

EPM (2011). Sistema de generación de energía de EPM. Recuperado de http://www. epm.com.co/site/Home/Institucional/ Nuestrasplantas/Energ\%C3\%ADa/ Centraleshidroel\%C3\%A9ctricas.aspx

Ferguson, J., \& Lohmann, L. (1994). The Anti-politics nachine: "Development" and bureaucratic power in Lesotho. The Ecologist, 24(5), 176-181.

Foucault, M. (1980). Power/Knowledge, Selected interviews and other writings 19721977. Nueva York, Estados Unidos: Pantheon Books.

Foucault, M. (2008). Segurança, território, população. San Pablo, Brasil: Martin Fontes.

González, F. (2014). Poder y violencia en Colombia. Bogotá, Colombia: Ediciones Antropos.

Guedes, A. (2006). Projeto identitário, discurso e pedagogia na constituição de um sujeito coletivo: o caso do movimento dos atingidos por barragens. (Tesis de maestría) Instituto de Investigación y Planeación Urbana y Regional (IPPUR), Universidad Federal, Río de Janeiro.

Guedes, A. (2011). O Trecho, as Mães e os Papéis. Movimentos e Durações no Norte de 
Goiás. 469 f. (Tesis doctoral) Museo Nacional, Universidade Federal do Rio de Janeiro.

Harvey, D. (2005). El "nuevo" imperialismo: acumulación por desposesión. Socialist register, 99-129.

Miller, P., \& Rose, N. (2012). Governando o presente: gerenciamento da vida econômica, social e pessoal. Ferreira-Valerio, P. (Trad.). São Paulo: Paulus.

Muñoz, G. (2015). Formas de violencia en la construcción de la central hidroeléctrica Porce III en Antioquia, Colombia. Cuadernos de Trabajo Red WATERLAT-GOBACIT, 2(2), 59-81.

Muñoz, G. (2016). De atingido a empreendedor: a política em tempos de "Gestão Social". O caso da Usina Hidrelétrica Porce III na Colômbia. (Tesis doctoral) Instituto de Investigación y Planeación Urbana y Regional (IPPUR), Universidad Federal, Río de Janeiro.
Palacios, M. (2003). Entre la legitimidad y la violencia: Colombia 1875-1994. Bogotá, Colombia: Grupo Editorial Norma.

Vainer, C., \& Araújo, F. (1990). Implantação de grandes hidrelétricas: estratégias do setor elétrico e estratégias das populações atingidas. Travessia, 6, 18-24.

Vélez, S., et al. (2006). Evaluación ex-post del programa de reasentamiento poblacional del proyecto hidroeléctrico Porce II. CIER, 15(49), 38-47.

Vieira, F. (2003). O Movimento de Atingidos por Barragens e a Comissão Mundial de Barragens: características e limites da participação política de um movimento social na escala global. En: Anais do X Encontro Nacional da ANPUR. Belo Horizonte, mayo de 2003. Recuperado de http://anpur.org.br/project/ anais-do-x-ena/ 